Ravi Kumar

Somnath Chattopadhyaya

Aniruddha Ghosh

Grzegorz M. Krolczyk

Pedro Vilaca

Ratnesh Kumar

Madhulika Srivastava

Mohammad Shariq

Rupam Triphathi

DOI: $10.21278 /$ TOF.41206

ISSN 1333-1124

eISSN 1849-1391

\title{
CHARACTERIZATION OF FRICTION SURFACED COATINGS OF AISI 316 TOOL OVER HIGH-SPEED-STEEL SUBSTRATE
}

\begin{abstract}
Summary
Nowadays friction surfacing (FS) has become a popular solid state surface coating technology suitable for a range of substrates. The technology has the ability to produce coatings with marginal dilution and good metallurgical bonding. The present study has aimed at producing a single-track and a three-track overlapping coatings on high-speed steel substrates using an AISI 316 consumable rod. Microhardness of coatings was examined by a Vickers micro hardness tester. Coatings of all the friction surfaced samples in as-deposited condition showed significant hardness. The infrared thermography showed that the peak temperature achieved by the AISI 316 coating was about $1020^{\circ} \mathrm{C}$. The coatings, thus attained, were further analysed for their microstructural features and interfacial characteristics by using FE-SEM. The EDX analysis showed the presence of nickel, chromium and oxygen, which indicates the formation of oxide compounds. The formation of AISI 316 deposits on the HSS substrate and the effect of coating overlapping are discussed in this article.
\end{abstract}

Key words: $\quad$ Friction surfacing, overlapping coatings, micro hardness, infrared thermography, AISI 316, Field Emission Scanning Electron Microscopy (FE-SEM).

\section{Introduction}

Friction Surfacing (FS) is a solid state surface modification technique. It involves the deposition of solid state coating over substrates for enhancing surface properties of the components with the aid of heat. A simple schematic arrangement of the FS process is shown in Fig. 1. There is a stationary substrate with which a rotating consumable rod is brought in contact under load. Initially, when the rotating rod is brought in contact with the substrate, heat is generated due to friction between the contacting surfaces. This initial stage is called a 
R. Kumar, S. Chattopadhyaya, A. Ghosh, G.M. Krolczyk, P. Vilaca, R. Kumar, M. Srivastava, M. Shariq, R. Triphathi
Characterization of Friction Surfaced Coatings of AISI 316 Tool over High-Speed-Steel Substrate

dwell time stage, during which the consumable rod gets sufficiently heated and plasticized. After the dwell time, transverse linear motion is introduced between the rod and the substrate. This facilitates the deposition of plasticized consumable rod above the substrate by shearing. Diffusion across the interface promotes bonding which occurs due to the application of heat and pressure between the two materials. Consequently, a result is the formation of a solid phase metallurgical bond as shown in Fig. 1. A lateral movement of the substrate, relative to the rotating consumable, deposits this plasticized material onto the substrate. The substrate material does not melt, and, therefore, there is no dilution of the substrate. The composition of the deposited coating is almost the same as that of the consumable. The deposit is integrally homogeneous and possesses good mechanical strength and adherence. FS is considered to be suitable mainly for producing homogeneous fine grained coatings, which have superior antiwear or anti-corrosion properties [1]. Another vital field where this technique can be considered is the renovation and repair of worn engineering components, i.e. dies and related tools, which might have developed surface cracks due to thermal fatigue [2].

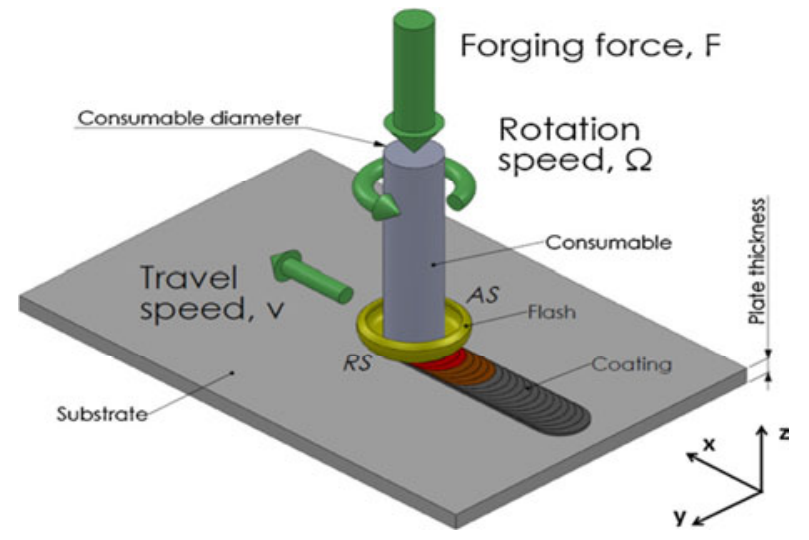

Fig. 1 Schematic diagram of friction surfacing process [3]

\section{Literature Overview}

The concept of FS was first reported by Klopstock and Neelands in 1941 in their patent for metal coating [4]. Since the development of the process, researchers have analysed combinations of different substrates and coatings in this field. Dilip et al. [5] discovered a possibility of employing FS as an alternative solid-state surface coating method for the layerby-layer manufacture of three-dimensional metallic parts. In their study, Kumar et al. [6] made an attempt to establish a relationship between the FS process parameters and physical dimensions of AA6063 aluminium alloy coating applied on IS2062 mild steel. They also studied the impact of FS on strength and ductility of the coating. Dilip et al. [7] showed that the process invariably leads to overaging of the strengthening precipitates in the heat treatable aluminium alloy 2014. Stegmueller et al. [8], designed an experimental setup to relate the principal process parametric connections using the standard methodology to FS with the addition of inductive heating. They discussed the effects of inductive heating on applying stainless steel to an aluminium substrate by friction surfacing. Jujare et al. [9] presented their study on the feasibility of deposition of copper on mild steel using the FS method. In their study, Hanke et al. [10] used the FS process to apply self-mating layers on cold work tool steels that are utilized for the deep-drawing of dies in the automotive industry. Nowadays, researchers are studying the surface morphology and topography of the welded joints. They are focusing on the role of emulsion mist formation on machining in the cutting zone [11]. In future, the study can be extended to friction surfaced samples for better insights $[12,13]$.

Vilaca et al. [14] explained the differences between the secondary and the primary flash formation on coatings produced on the HSS substrate with an AISI 316 consumable rod in the 
Characterization of Friction Surfaced Coatings of AISI 316 Tool over High-Speed-Steel Substrate
R. Kumar, S. Chattopadhyaya, A. Ghosh, G.M. Krolczyk, P. Vilaca, R. Kumar, M. Srivastava, M. Shariq, R. Triphathi

FS process. They compared the influence of secondary and primary flash formation on coatings in detail via Scanning Electron Microscopy (SEM) and Electron Backscatter Diffraction (EBSD). They also observed that the secondary flash formation has a beneficial effect on the FS process efficiency and the hardness of the coating, which supersedes the hardness of the HSS substrate. Gandra et al. [15] analysed the use of FS for the deposition of AA6082-T6 on the AA2024-T3 substrate. They also pointed out the influence of FS on the bending, the tensile and the wear characterization. Puli et al. [16] explained microstructural transformations in depositing AISI $440 \mathrm{C}$ on mild steel by the FS method; these transformations resulted in the transformation from ferrite to austenite and the dissolution of certain amount of carbide during the heating stage. The coatings exhibited a hardness value of approximately $590 \mathrm{HV}$. Using SEM imaging and image analysis, Kaplonek et al. [17] investigated spherical melted chips formed during the grinding process and carried out an analysis of the obtained SEM micrographs to determine the selected geometrical parameters describing the morphological features of the assessed chips. Jozwik et. al [18] presented functional relationships between surface geometry parameters, feed rate, and vibration level in the radial direction of the workpiece. Further research on the FS of martensitic stainless steels was reported by Puli et al. [19], with special focus on shear and bend testing. Puli et al. [20] also highlighted the deposition of AISI 316L on the mild steel substrate. According to their study, microscopy measurements revealed numerous stacking faults and high dislocation density, as anticipated considering the extensive plastic deformation involved in the FS process. The low temperature achieved during the FS process prevented the formation of $\delta$ ferrite, which contributes to the improvement of the anticorrosion property of the FS coatings with respect to those obtained by manual metal arc welding. Maruda et al. [21] investigated the influence of conditions of emulsion and oil mist forming on the chip shape and the surface roughness of $\mathrm{X} 10 \mathrm{CrNi} 18-8$ stainless steel during turning and found that, under minimum quantity cooling lubricant (MQCL) and minimum quality lubricant (MQL) conditions, the area of formation of elemental chips and the ones in the shape of short spirals is wider than that produced by dry turning.

Govardhan et al. [22] suggested prospective uses of FS in the manufacture of pumps for chemicals and of petrochemical pressure vessels, based on the corrosion performance studies on austenitic stainless steel deposited on mild steel. Rao et al. [23] presented a viability study on the production of friction surfaced coatings for nonferrous substrates. They attempted FS using consumable rods made of low carbon steel, commercially pure copper, aluminium alloy (AA6063), and titanium on the commercially pure aluminium, magnesium (ZM21), copper, titanium alloy (Ti-6Al-4V) and Inconel 800 substrates. The obtained coatings exhibited fine grain microstructures with better properties than the original material. Zavareh et al. [24-26], in the three studies, focused on applying protection to carbon steel surfaces by means of coating techniques such as thermal spraying. In the first study they deposited a thin layer of $\mathrm{Cr}_{3} \mathrm{C}_{2}-\mathrm{NiCr}$ on carbon steel [24]. In the second, they applied the $\mathrm{Al}_{2} \mathrm{O}_{3}-40 \mathrm{wt} \% \mathrm{TiO}_{2}$ composite coating on carbon steel surface [25]; and, in the third study, they deposited the $\mathrm{Al}_{2} \mathrm{O}_{3}-13 \% \mathrm{TiO}_{2}$ or $\mathrm{Cr}_{3} \mathrm{C}_{2}-25 \% \mathrm{NiCr}$ composite powder coatings on carbon steel samples [26]. A further analysis of those coatings was carried out using SEM, wear test (pin-on-disk), potentiodynamic polarization, and electrochemical impedance spectroscopy (EIS). Those investigations were mainly done to study the wear-resistance and corrosionresistance properties of the sample coatings in aggressive environments. The sample coatings showed high corrosion resistance and significantly improved wear resistance. That research was undertaken to improve the behaviour in salt water of carbon steel piping used in the sea transport of crude oil. Further advancement in the study of tribological behaviour will open new horizons for research on this aspect and will be helpful in understanding tribological properties of the present material combination in FS. In connection with this, Ruggiero et al. 
R. Kumar, S. Chattopadhyaya, A. Ghosh, G.M. Krolczyk, P. Vilaca, R. Kumar, M. Srivastava, M. Shariq, R. Triphathi
Characterization of Friction Surfaced Coatings of AISI 316 Tool over High-Speed-Steel Substrate

$[27,28]$ investigated both the mechanical and the tribological behaviour of glass fibre and carbon fibre-reinforced epoxy, taking into account the influence of the production parameters on the content of laminate voids. Also, Merola et al. [29] validated a new protocol to measure surface roughness on retrieved femoral heads by using the aforementioned two different acquisition techniques. According to them all femoral components of their investigation showed remarkable differences in roughness values.

The present study demonstrates the FS process using an AISI 316 tool on high speed steel substrates with single and multiple tracks. The micro hardness test of the obtained coatings was conducted using a Vickers micro hardness tester. Furthermore, to analyse the bonding mechanism, infrared thermography was carried out using an infrared (IR) camera. The coatings were further analysed for their interfacial characteristics and microstructural features by using FE-SEM. A successful deposition of AISI 316 on high speed steel presented new prospects for numerous industrial applications of FS. On the basis of the existing literature survey, it can be claimed that so far this type of study on three-track overlapping coatings has not been done with this particular material combination. Hence, the novelty of the present work is well justified.

\section{Materials and Methods}

\subsection{Materials}

The base material used as the substrate plate was a high-strength steel (HSS): Optimum $700 \mathrm{MC}$ Plus, with the following chemical composition:

Table 1 Chemical composition of HSS substrate plate [14]

\begin{tabular}{|l|l|l|l|l|l|l|}
\hline Elements & $\% \mathrm{C}$ & $\% \mathrm{Si}$ & $\% \mathrm{Mn}$ & $\% \mathrm{P}$ & $\% \mathrm{~S}$ & $\% \mathrm{Al}$ \\
\hline Wt.\% & 0.10 & 0.25 & 2.10 & 0.02 & 0.01 & 0.015 \\
\hline
\end{tabular}

This structural steel was thermo-mechanically rolled and cold-formed. The original thickness of the plate was $7.6 \mathrm{~mm}$. From the side of the plate to be coated, a piece having thickness of $0.6 \mathrm{~mm}$ was extracted by milling and then degreased prior friction surfacing. This procedure prevented the formation of the irregular and oxidised material surface and ensured uniform conditions on the material surface during testing. The main mechanical properties of HSS are as follows:

Table 2 Main mechanical properties of the HSS used in testing [14]

\begin{tabular}{|c|c|c|c|c|}
\hline Material & Symbol & Description & Value & Units \\
\hline \multirow{3}{*}{ Substrate } & $\sigma_{\text {yield }}$ & Yield stress & 742 & $\mathrm{MPa}$ \\
\cline { 2 - 5 } & $\sigma_{\max }$ & Ultimate strength & 832 & $\mathrm{MPa}$ \\
\cline { 2 - 5 } & & Hardness & $270 \mathrm{HV} 10$ & \\
\hline Consumable Rod & & Hardness & $254 \mathrm{HV} 10$ & \\
\hline
\end{tabular}

The material used as a consumable rod was the austenitic stainless steel AISI 316; its chemical composition is shown in Table 3. The original diameter of the rod was $22 \mathrm{~mm}$.

Table 3 Chemical composition of consumable rod [14]

\begin{tabular}{|l|l|l|l|l|l|l|l|l|}
\hline Elements & $\% \mathrm{C}$ & $\% \mathrm{Cr}$ & $\% \mathrm{Ni}$ & $\% \mathrm{Si}$ & $\% \mathrm{Mn}$ & $\% \mathrm{Mo}$ & $\% \mathrm{P}$ & $\% \mathrm{~S}$ \\
\hline Wt.\% & 0.08 & 17.0 & 12.0 & 1.0 & 2.00 & 2.50 & 0.045 & 0.03 \\
\hline
\end{tabular}


Characterization of Friction Surfaced Coatings of AISI 316 Tool over High-Speed-Steel Substrate
R. Kumar, S. Chattopadhyaya, A. Ghosh, G.M. Krolczyk, P. Vilaca, R. Kumar, M. Srivastava, M. Shariq, R. Triphathi

\subsection{FS Process and Parameters}

The FS process was conducted as a single-line deposition and multi-line deposition (in the case of overlapping coatings) in a length of about $90 \mathrm{~mm}$ by using an ESAB LEGIO ${ }^{\mathrm{TM}}$ 5UT numerical control machine. The maximum power of its spindle was $30 \mathrm{~kW}$. The control of the FS process was done with plunge speed control. The material for the FS experiments was selected according to the requirement of developing a thick coating of high corrosion resistance (for marine environments due to the Molybdenum (Mo) content of the steel) to be applied on a substrate of high mechanical strength. In addition, the coating was supposed to have good heat resistance. Having these properties, the coating can lengthen the life of a tool made of HSS. In the past, such coatings contained titanium nitride (TiN), which is costly. Today, a similar coating property could be attained by a coating of mild steel on a HSS substrate, which is less costly than TiN. This type of coating can be used on products used in processing, such as machine knives, and in industrial operations where the cutting life and scheduled tooling changes are important factors.
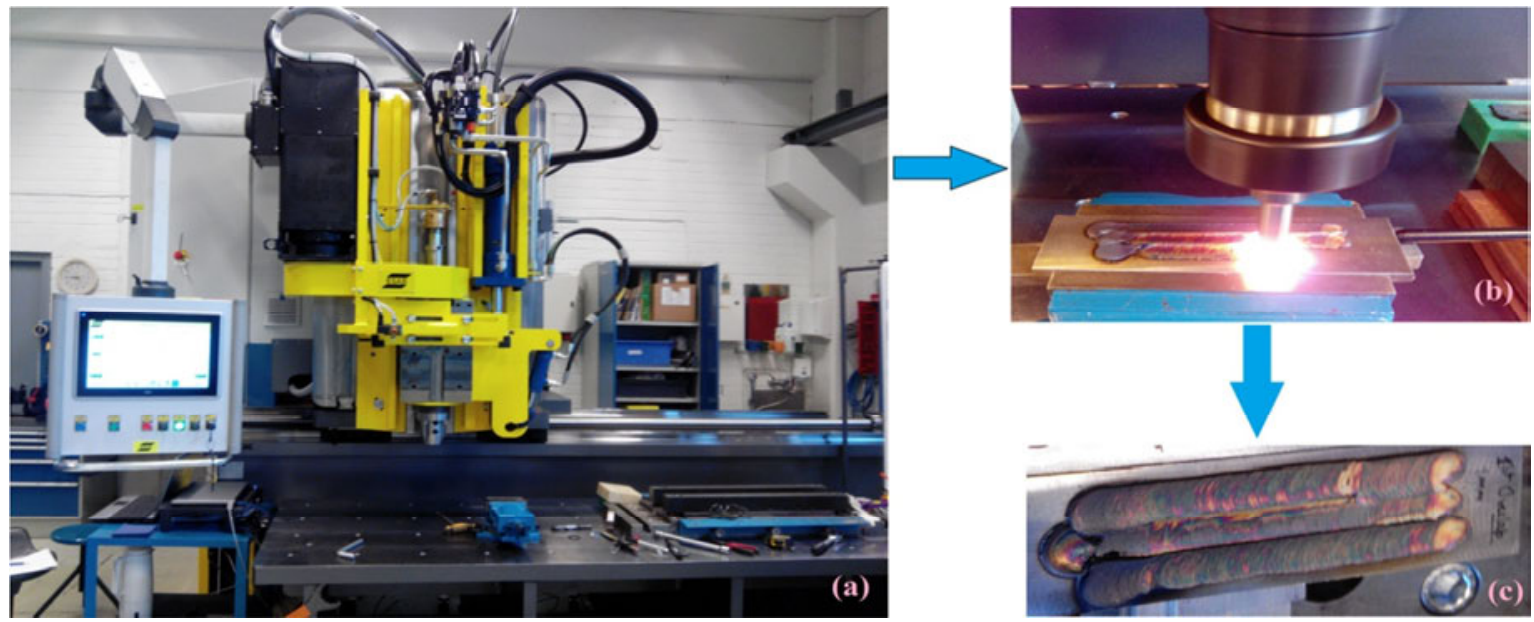

Fig. 2 (a) Friction surfacing equipment, (b) Friction surfacing process, (c) Obtained sample

Table 4 The parameters of friction surfacing process

\begin{tabular}{|l|c|c|l|l|c|}
\hline $\begin{array}{l}\text { Process } \\
\text { Parameters }\end{array}$ & Spindle rotation speed, $\Omega$ & $\begin{array}{l}\text { Plunge speed } \\
\text { during FS, Vz }\end{array}$ & $\begin{array}{l}\text { Travel } \\
\text { speed, Vx }\end{array}$ & $\begin{array}{l}\text { Axial } \\
\text { force }\end{array}$ & $\begin{array}{l}\text { Mechtrode dwell } \\
\text { time }\end{array}$ \\
\hline Value & $\begin{array}{c}2500 \mathrm{rpm} \text { (clockwise } \\
\text { direction) }\end{array}$ & $120 \mathrm{~mm} / \mathrm{min}$ & $300 \mathrm{~mm} / \mathrm{min}$ & $0.73 \mathrm{kN}$ & $30 \mathrm{sec}$ \\
\hline
\end{tabular}

The initial plunge (at $V_{x}=0$ ) was $2 \mathrm{~mm}$ in depth at a speed of $V z=60 \mathrm{~mm} / \mathrm{min}$. These parameters were determined on the basis of trials from earlier experiments. The dimensions of the substrate plates were $120 \mathrm{~mm}$ (length) x $40 \mathrm{~mm}$ (width) x $7 \mathrm{~mm}$ (thickness). During the FS tests, the substrate plates were laid down over a planar rigid anvil and were clamped at the sides parallel to the travel direction of consumable rod. Fig. 2 shows a schematic diagram of the experimental arrangement. Fig. 3(a), (b), (c) and (d) show the coating samples produced. 

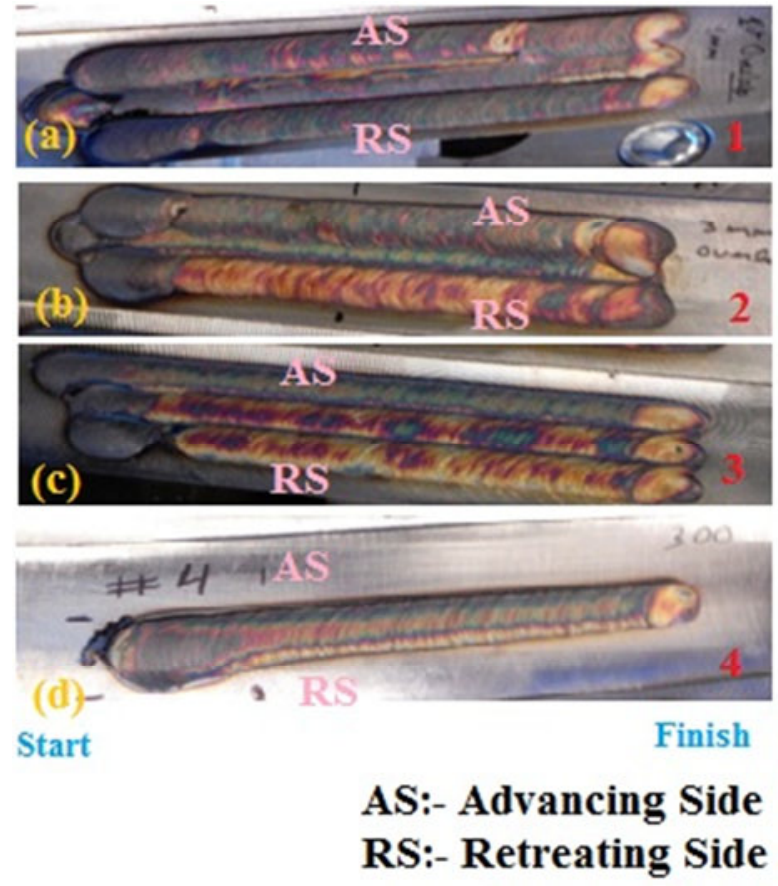

Fig. 3 (a) Sample 1 having a $1 \mathrm{~mm}$ overlap on both sides, (b) Sample 2 having a $3 \mathrm{~mm}$ overlap on both sides, (c) Sample 3 having a $3 \mathrm{~mm}$ overlap stepwise, (d) Sample 4 having a single coating

\subsection{Testing Equipment}

An FLIR A320 infrared camera was employed to record temperature during the FS process. This camera has a $0.08^{\circ} \mathrm{C}$ thermal sensitivity and was adjusted to operate within a temperature range of $80^{\circ} \mathrm{C}$ to $1200^{\circ} \mathrm{C}$ with a $9 \mathrm{~Hz}$ image acquisition frequency. This device permits the measuring of temperatures at exposed surfaces, such as revolving flash that includes consumable rod extremity. Hence, temperature at the inner rubbing interface may attain a higher value than what is measured. A Vickers Micro Hardness Tester MXT-70 was used for measuring the micro hardness of different samples of the coating and the substrate. An FE-SEM Supra 55 was used for the microstructural analysis of the coating used in the experiment.

\section{Results and Discussions}

\subsection{Infrared Thermography}

In the FS process, the heat generated due to rubbing between the rotating consumable rod and the substrate is a key factor in successful coating formation. As the consumable rod rotates at a very high speed and the concomitant vibrations are also transmitted to the substrate during the process, it becomes very challenging to measure temperature by means of thermocouples. Therefore, for measuring temperature, a non-contact type temperature measurement technique was applied in this study by using an IR camera. The IR camera is capable of measuring the temperature generated during different stages of the FS process in a single step. The time-temperature plot shown in Fig.4 (a) gives a thermal profile from the start of the process to its steady state. There is a slow increase in temperature as the rod starts rubbing against the substrate due to friction. After some time, the temperature rises sharply. At the start of the process, the friction is considered to be dry friction and the complete system unsteady. In a short time, a high degree of frictional heat is generated. Since the time for heat diffusion is very short, the energy tends to focus at the interface. This creates a situation of 
Characterization of Friction Surfaced Coatings of AISI 316 Tool over High-Speed-Steel Substrate
R. Kumar, S. Chattopadhyaya, A. Ghosh, G.M. Krolczyk, P. Vilaca, R. Kumar, M. Srivastava, M. Shariq, R. Triphathi

adiabatic heating with a rapid rise in temperature, causing a large temperature gradient. The beginning of plasticization of the material happens during this period by the transformation of dry friction into lubricated friction [30]. The process gets into a steady state once it reaches the peak temperature with a decline in the frictional torque. The highest temperature measured is about $1020^{\circ} \mathrm{C}$, which is shown in a thermal image in Fig.4 (b).

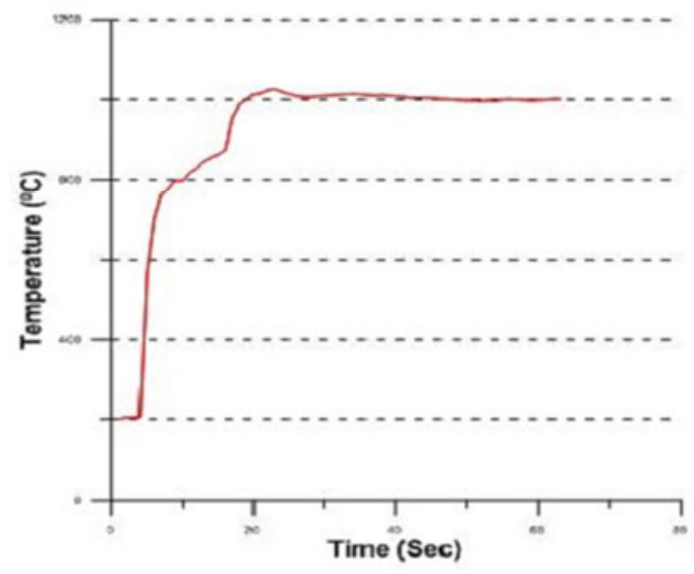

Fig. 4 (a) Time-temperature plot obtained from the AISI 316 tool /HSS substrate interface

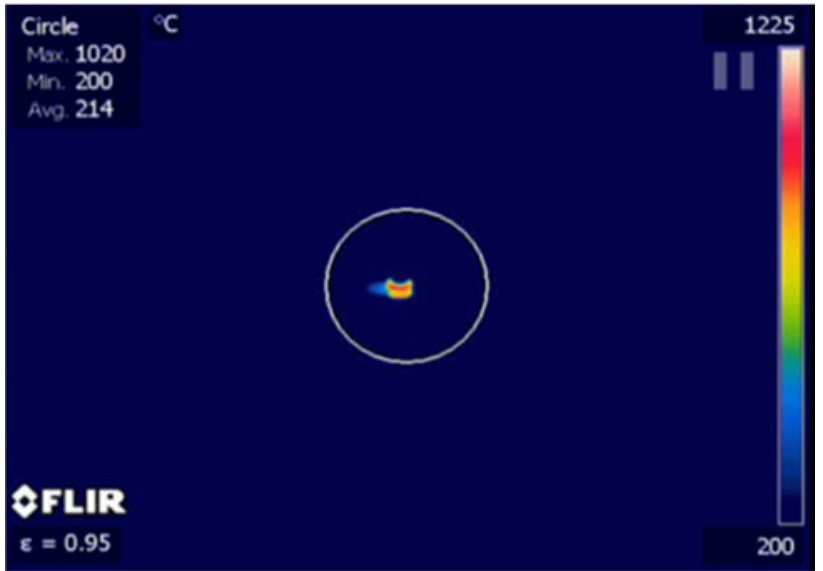

Fig. 4 (b) Thermal image showing the maximum temperature reached in the AISI 316 tool/ HSS substrate interface

\subsection{Process Mechanism of Friction-surfaced Coating Formation}

Whether a consumable rod produces a coating on the substrate or not depends on its flow stress. The flow stress of consumable rod is a function of temperature and local strain rate [31]. Flow stress drops significantly with both strain rate and temperature. The FS process includes relatively high strain rates. During the process, a relatively high temperature close to that of the melting point is generated [32]. In the FS technique, a hot plasticized layer is compressed between the rod and the substrate. In this instance, a sharp decline in flow stress due to exposure to a very high temperature is undesirable for getting a surface coating. The plasticized material at the interface should retain a certain amount of flow stress, which should at least match the localized stress generated due to axial loading. If the flow stress of the plasticized material is low for a given temperature, then it will be extruded in the form of flash. If the flow stress is equivalent to the localized stress, the material will face a degree of resistance to plastic flow and will intermingle with the substrate to form a coating [33].

In the present study, it was establish that the AISI 316 tool coating could be applied on the HSS substrate with ease because at the reached steady state temperature $\left(1020^{\circ} \mathrm{C}\right)$, AISI 316 had enough flow stress to offer resistance to plastic flow and intermingle with the substrate to form a coating.

\subsection{Micro hardness}

Before conducting the test, the samples were cross-sectioned and polished by a BAINPLO METCO semi-automatic grinding and polishing machine. To get the micro hardness values of the overlapping coatings, indentations were made at five different points, i.e., A, B, C, D and E, along the coating as shown in Fig. 5. In the case of the substrate, indentations were made at a perpendicular direction of the coating and the substrate interface at three different sections with a load of $1 \mathrm{kgf}$ for a dwell time of 15 seconds. The distance of 
R. Kumar, S. Chattopadhyaya, A. Ghosh, G.M. Krolczyk, P. Vilaca, R. Kumar, M. Srivastava, M. Shariq, R. Triphathi
Characterization of Friction Surfaced Coatings of AISI 316 Tool over High-Speed-Steel Substrate

indentations from the interface was kept at $1 \mathrm{~mm}, 3.5 \mathrm{~mm}$, and $6 \mathrm{~mm}$ as shown in Fig. 5. The values of micro hardness obtained in that way are presented in Table 5 for the obtained FS coatings on four samples. As for the substrate, it is plotted graphically and sample-wise, as shown in Fig. 6 (a, b, c \& d).

Table 5 The average hardness values of obtained coating after FS

\begin{tabular}{|c|c|}
\hline Sample & Average Hardness Values (HV) \\
\hline 1 & 445 \\
\hline 2 & 441 \\
\hline 3 & 448 \\
\hline 4 & 459 \\
\hline
\end{tabular}

The following trend in micro hardness values in the obtained coating can be observed: at points $\mathrm{B}$ and $\mathrm{D}$, these values are greater in comparison with points $\mathrm{A}, \mathrm{C}$ and $\mathrm{E}$ in samples 1 , 2 , and 3, which represents the overlapping region of the coating in all the three samples. The average microhardness value in the case of single coating (sample 4) is $287 \mathrm{HV}$. The friction surfaced coatings show higher hardness values than the hardness of 254 HV10 of the consumable rod in as-received condition. Similar results were noticed with the substrate hardness after FS. A higher hardness value was noted in the surface closer to the coating in the sample having $3 \mathrm{~mm}$ overlaps on both sides as shown in Fig. 6 (b). A similar trend was noted in the sample having a 1mm overlap as shown in Fig.6 (a). However, in the case of the sample having a single coating and the sample having a $3 \mathrm{~mm}$ overlap in steps, an increase in hardness from the interface to the substrate was noted Fig. 6(c), (d). These variations are due to microstructures formed at the interface as a result of heating and cooling conditions that the materials are subjected to together with plastic deformation that occurred during the process. It is an important aspect for applications that seek to minimise wear resistance.

The hardness value of the substrate after FS is found to be higher than that of the substrate in as-received condition.

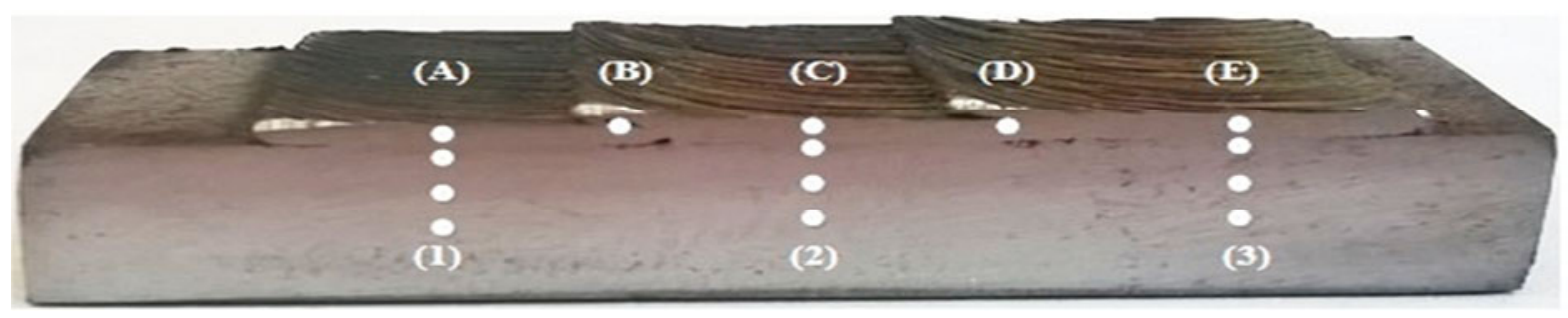

Fig. 5 Cross-section of the coating of sample 3 (a $3 \mathrm{~mm}$ overlap in steps) showing indentations at different points and sections during micro hardness testing

Table 6 The micro hardness values of overlap coatings.

\begin{tabular}{|l|c|c|c|c|c|}
\hline \multirow{2}{*}{ Samples Details } & \multicolumn{5}{c|}{ Micro hardness testing points on coatings } \\
\cline { 2 - 6 } & A & B & C & D & E \\
\hline SAMPLE 1 (1 mm overlap both sides) & 295 & 373 & 275 & 348 & 262 \\
\hline SAMPLE 2 (3mm overlap both sides) & 293 & 341 & 316 & 317 & 305 \\
\hline SAMPLE 3 (3 mm overlap step) & 288 & 283 & 278 & 316 & 263 \\
\hline
\end{tabular}


Characterization of Friction Surfaced Coatings of AISI 316 Tool over High-Speed-Steel Substrate
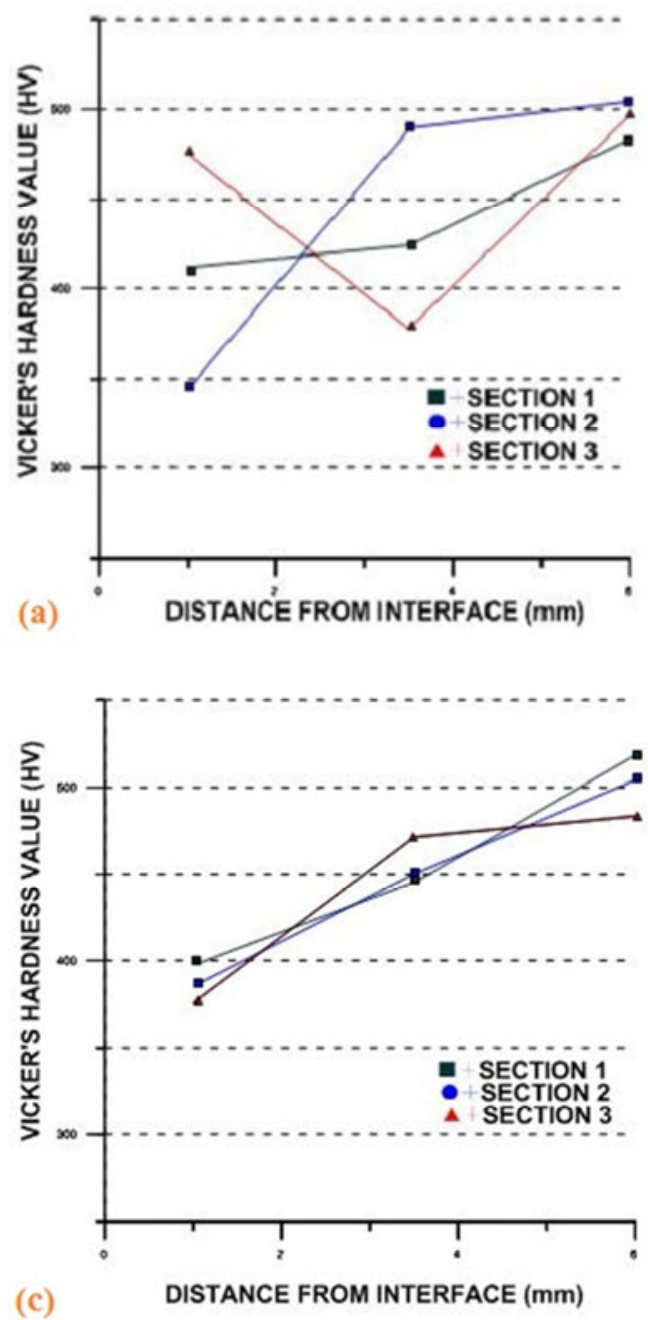

R. Kumar, S. Chattopadhyaya, A. Ghosh, G.M. Krolczyk, P. Vilaca, R. Kumar, M. Srivastava, M. Shariq, R. Triphathi

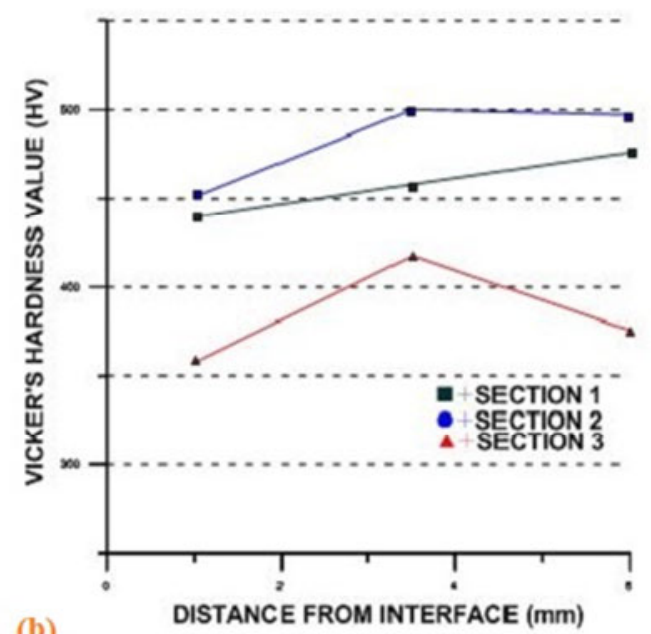

(b)

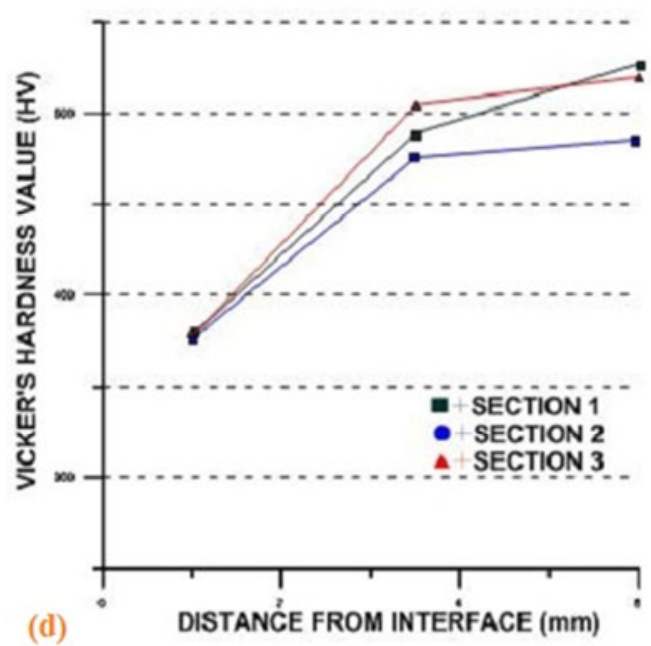

Fig.6 Micro hardness distribution of (a) Sample 1 having a $1 \mathrm{~mm}$ overlap on both sides (b) Sample 2 having a $3 \mathrm{~mm}$ overlap on both sides (c) Sample 3 having a $3 \mathrm{~mm}$ overlap step-wise (d) Sample 4 having a single coating

From Fig. 6 one can note that the micro hardness value increases with an increase in the distance from the interface. In all the samples, the micro hardness value of the substrate is noted to increase after coating. This confirms that the hardness of the material increases after FS. A regular pattern of hardness variation is observed in Fig. 6 (d), i.e. in the sample with a single coating. The sample having a $3 \mathrm{~mm}$ overlap on both sides and that with step-wise overlapping have regular variations as compared to the sample having a $1 \mathrm{~mm}$ overlap on both sides. Such variations can be clearly seen in Figure6 (a), (b), and (c).

\subsection{Field Emission Scanning Electron Microscopy (FE-SEM)}

SEM was done on the transverse sections of the sample having $30 \mathrm{~mm}$ in length and 10 $\mathrm{mm}$ in width, which were metallurgically polished and etched with Nital solution containing $90 \%$ Ethanol and 10\% Nitric acid. Generally, the FS of steel alloys involves full austenization as the phase transformation of iron from the body-centred cubic (BCC) to the face-centred cubic (FCC) is required to achieve a visco-plastic state. Apart from grain refinement due to dynamic recrystallization, the hardening of coating is determined by quenching depending on the carbon content, alloying composition, and cooling rate [34]. The austenitic stainless steels have face-centred-cubic lattice structure of austenite throughout the entire temperature range of FS, i.e. from room temperature to the melting point [35]. As the material is rapidly cooled at room temperature, austenite transforms to martensite. Austenitic stainless steel is hardened 
R. Kumar, S. Chattopadhyaya, A. Ghosh, G.M. Krolczyk, P. Vilaca, R. Kumar, M. Srivastava, M. Shariq, R. Triphathi
Characterization of Friction Surfaced Coatings of AISI 316 Tool over High-Speed-Steel Substrate

and strengthened by cold work because it is not heat-treatable. Austenitic stainless steel has the best corrosion-resistance because of its high chromium content.

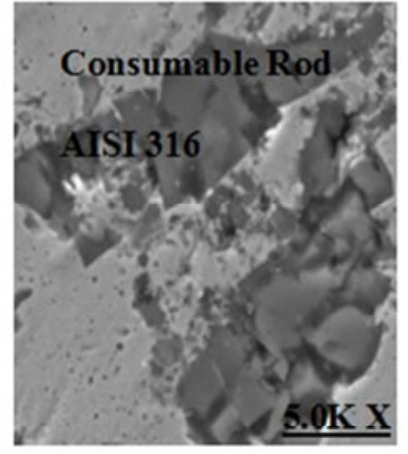

(a)

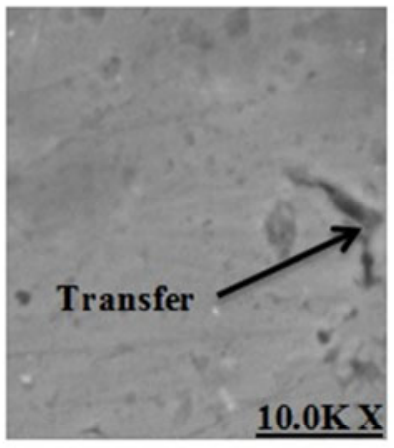

(d)

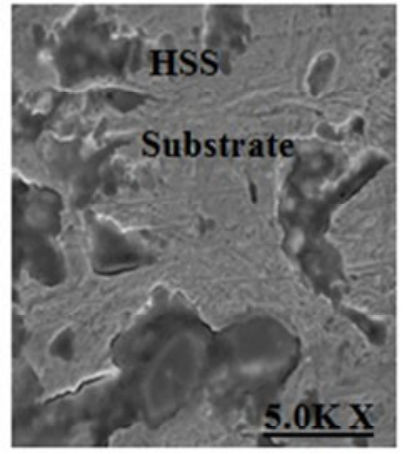

(b)

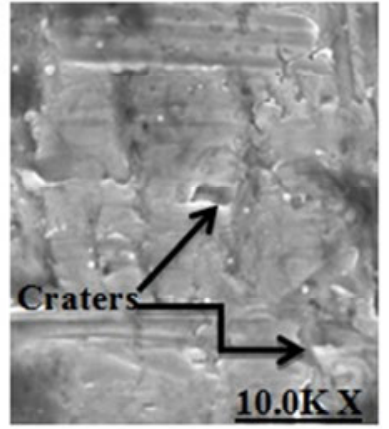

(e)

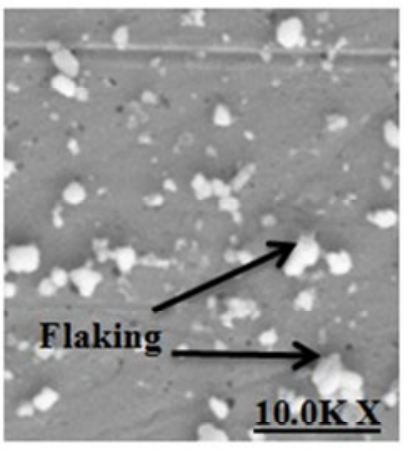

(c)

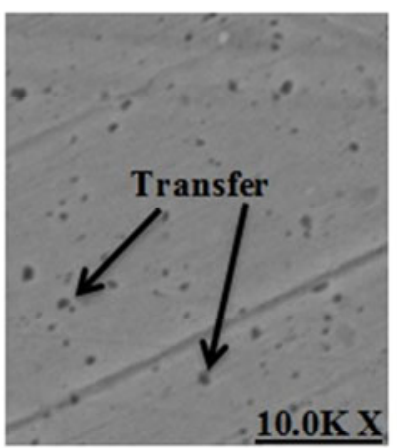

(f)

Fig. 7 SEM image of (a) Original consumable rod (b) Substrate (c) Coating of sample 1 having a $1 \mathrm{~mm}$ overlap on both sides (d) Coating of sample 2 having a $3 \mathrm{~mm}$ overlap on both sides

(e) Coating of sample 3 having a $3 \mathrm{~mm}$ overlap step-wise (f) Coating of sample 4 having a single coating.

The structure of consumable rod in Fig. 7(a) is an austenitic structure while the HSS substrate Fig. 7(b) shows a BCC structure. In most of the coatings, hardness measurement reveals an increase in hardness near the surface of the coating due to significant grain refinement. Vilaca et.al [14] observed that the grain refinement is a result of nucleation and the growth of new grains that occurs due to high strain rate characteristics of the solid state processing. Fig. 7(c), (d), (e), (f) show the SEM images of coatings in the produced samples. The SEM image of sample 1 shows a spherodite micro structure containing small particles of cementite and a continuous phase of austenite.

Puli et. al [16] described three important microstructural differences between FS and the standard heat treatment. Firstly, FS involves much shorter austenitization times despite a considerably higher temperature. The carbide particles, therefore, do not completely dissolve during FS. Secondly, in FS, the austenite grain quality is much finer. Thirdly, the cooling rate in FS is much higher, mainly due to rapid heat conduction through the substrate material [35]. The multi-layered overlapping of $3 \mathrm{~mm}$ and $1 \mathrm{~mm}$ gives a possibility of wide area coverage in FS. However, the main objective in multi-layering is to ensure good bonding between successive tracks of the deposited material. Puli et.al [16] established that good inter-track bonding can be achieved only when good frictional contact occurs between the edge of previously deposited track and the rotating mechtrode while depositing the next track. In this 
Characterization of Friction Surfaced Coatings of AISI 316 Tool over High-Speed-Steel Substrate
R. Kumar, S. Chattopadhyaya, A. Ghosh, G.M. Krolczyk, P. Vilaca, R. Kumar, M. Srivastava, M. Shariq, R. Triphathi

experiment, a three-track coating was successfully produced with good bonding as shown in Fig. 8 (a), (b) and (c).

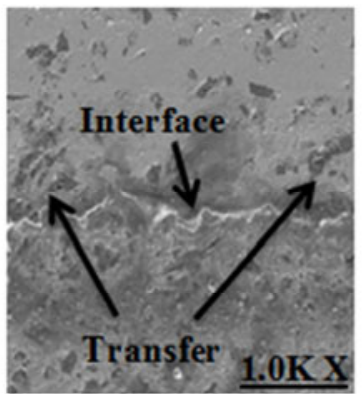

(a)

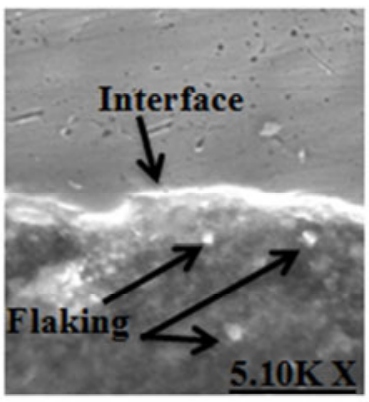

(b)

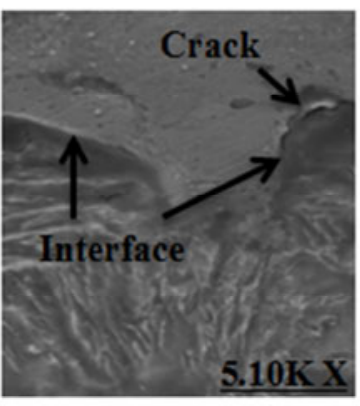

(c)

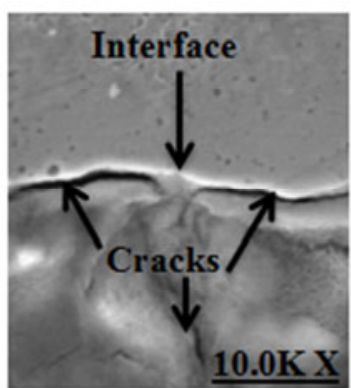

(d)

Fig. 8 SEM images at the interface of (a) Sample 1 having a1 $\mathrm{mm}$ overlap on both sides (b) Sample 2 having a $3 \mathrm{~mm}$ overlap on both sides (c) Sample 3 having a $3 \mathrm{~mm}$ overlap step-wise (d) Sample 4 having a single coating

The interface between the coating and the substrate in sample 3 having a $3 \mathrm{~mm}$ overlap (Fig. 8(c)) shows intermixing of the material. The waviness of the interface gives evidence of chemically active surfaces being generated, where a solid state joining mechanism by diffusion and atomic binding is activated. This intermixing leads to bonding between the coating and the substrate. The orientation of the grain and boundaries between the smaller BCC grains of the substrate and the larger FCC grains of the coating is also a strong evidence of the bonding of the friction surfaced coatings [14]. However, crack formation at the interface of the coating and the substrate of a single layer in Fig. 8(d) shows a lack of bonding at the edges of the coating.

\subsection{Energy Dispersive X-ray (EDX) Spectroscopy}

During the friction surfacing of AISI 316 stainless steel over HSS, the deposition of consumable rod involves the formation of nickel compounds of manganese and chromium. The results of the EDX measurement in different samples are shown in Fig. 9 (a), (b), (c) and (d). The EDX measurement of floccus-like area in Fig. 9(a) shows that this area has a composition of about $55.27 \% \mathrm{Fe}, 19.44 \% \mathrm{Cr}, 7.16 \% \mathrm{Ni}, 6.68 \% \mathrm{O}, 5.43 \% \mathrm{Si}, 4.02 \% \mathrm{C}$, and $1.99 \%$ N. Fig. 9(b) shows that its floccus-like area has a composition of around $55.47 \% \mathrm{Fe}$, $16.91 \% \mathrm{Cr}, 8.37 \% \mathrm{Ni}, 8.50 \% \mathrm{O}, 2.06 \% \mathrm{Si}, 5.46 \% \mathrm{C}, 1.70 \% \mathrm{Mo}$, and $1.54 \% \mathrm{~N}$. Fig. 9(c) shows that its floccus like area has a composition of around $56.62 \% \mathrm{Fe}, 17.05 \% \mathrm{Cr}, 9.01 \%$ $\mathrm{Ni}, 7.46 \% \mathrm{O}, 1.86 \% \mathrm{Si}, 4.04 \% \mathrm{C}, 2.17 \% \mathrm{Mo}$, and 1.80\% N. In Fig. 9(d), the floccus-like area has a composition of around $64.39 \% \mathrm{Fe}, 17.63 \% \mathrm{Cr}, 12.66 \% \mathrm{Ni}, 1.65 \% \mathrm{O}, 0.30 \% \mathrm{Si}$, and $3.38 \% \mathrm{C}$. The analysis shows the presence of nickel, chromium, and oxygen, which indicates the formation of oxide compounds.

In samples $1,2,3$, and 4 , the carbon percentage increases by $4.02 \%, 5.46 \%, 4.04 \%$ and $3.38 \%$, respectively, as compared with the original consumable rod having $0.08 \%$ carbon. This results in an increase in hardness of the coating, which was verified by a micro hardness test. This is due to the re-precipitation of carbide particles during the plastic deformation. 
R. Kumar, S. Chattopadhyaya, A. Ghosh,

G.M. Krolczyk, P. Vilaca, R. Kumar,

M. Srivastava, M. Shariq, R. Triphathi
Characterization of Friction Surfaced Coatings of AISI 316 Tool over High-Speed-Steel Substrate

(a)

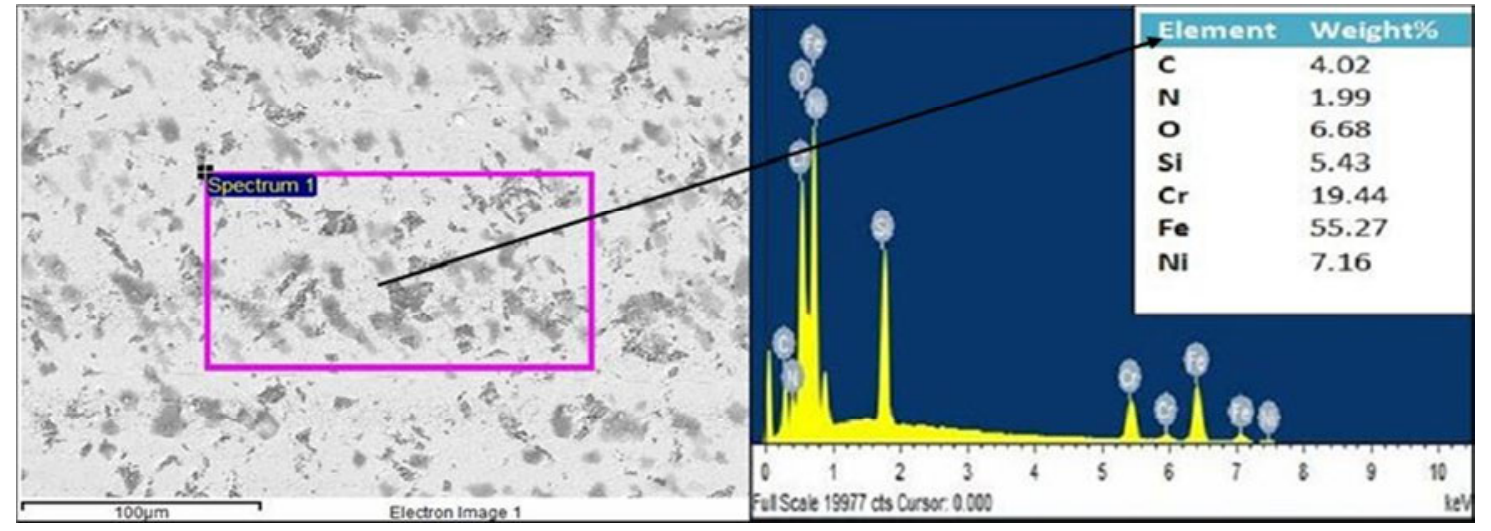

(b)

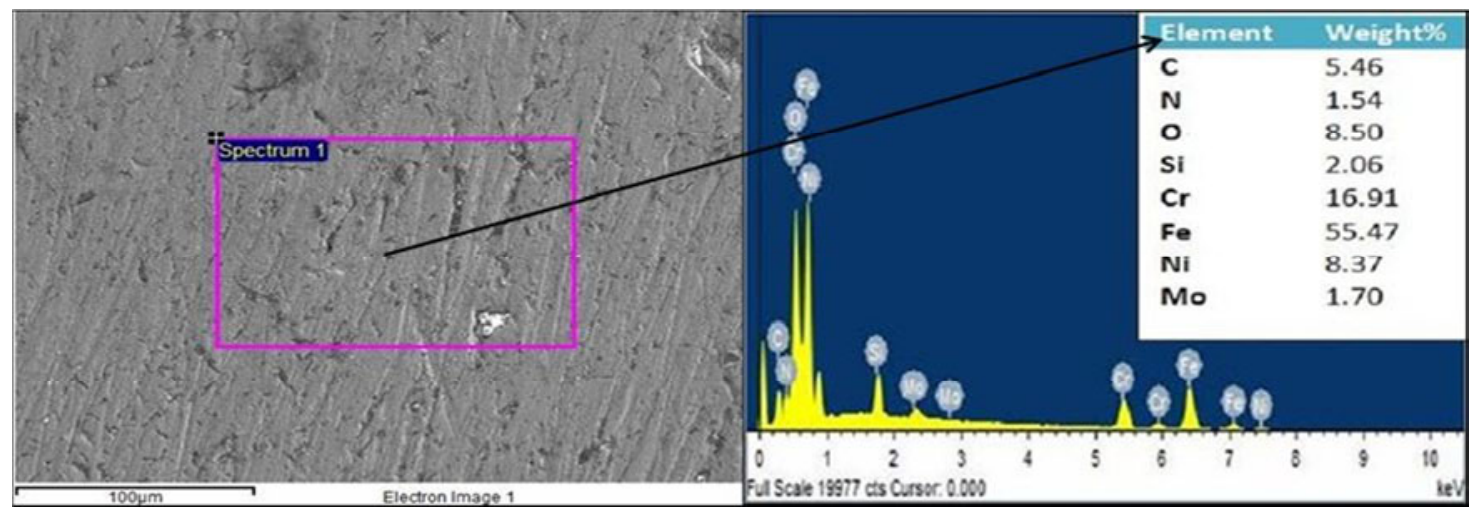

(c)

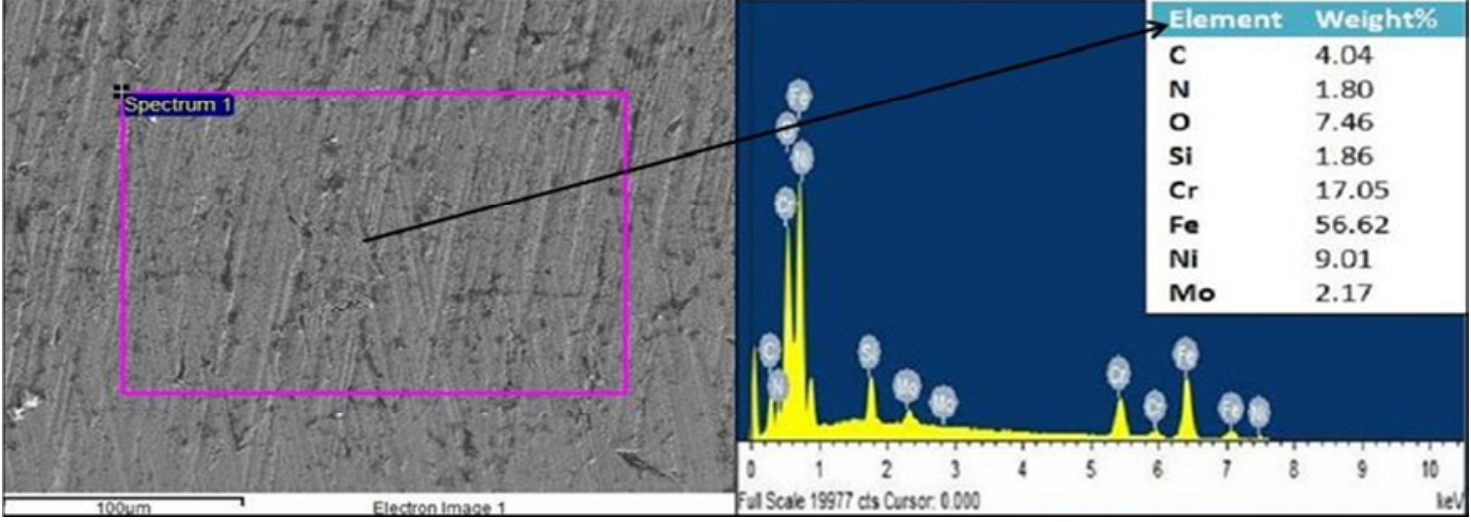

(d)

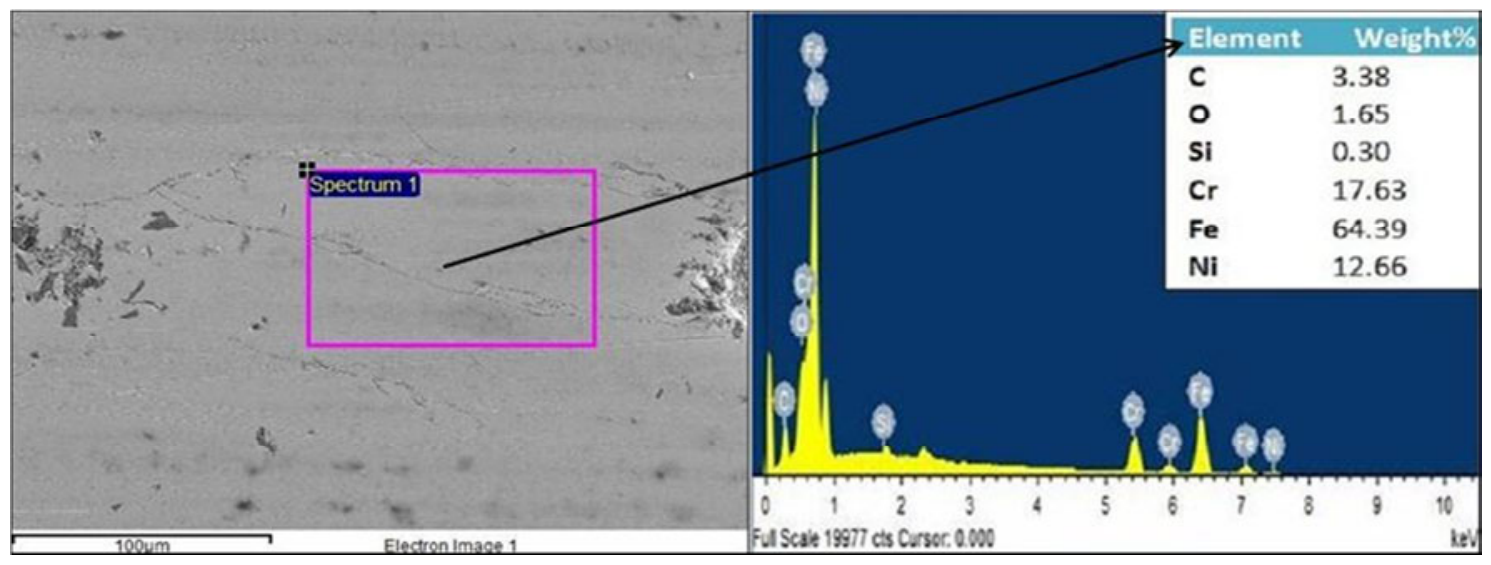

Fig. 9 EDX images (a) Sample 1 having a $1 \mathrm{~mm}$ overlap both sides (b) Sample 2 having a 3 mm overlap both sides (c) Sample 3 having a $3 \mathrm{~mm}$ overlap step wise (d) Sample 4 having a single coating 
Characterization of Friction Surfaced Coatings of

AISI 316 Tool over High-Speed-Steel Substrate
R. Kumar, S. Chattopadhyaya, A. Ghosh, G.M. Krolczyk, P. Vilaca, R. Kumar, M. Srivastava, M. Shariq, R. Triphathi

\section{Conclusions}

Experiments were conducted for a single layer and overlapping coatings using friction surfacing (FS) to deposit AISI 316 on HSS. Infrared thermography, micro hardness testing, FE-SEM and EDX were carried out to assess the efficacy of the coatings. The major conclusions drawn from the study can be summarized as follows:

I. Sound metallurgically-bonded AISI 316 single layer and overlapping coatings on HSS can be obtained by FS, except for the edges (in the case of overlapping coatings).

II. The peak temperature measured is around $1020^{\circ} \mathrm{C}$ during the FS in which an AISI 316 tool was used on the HSS substrate.

III. The AISI 316 coating can be applied on the HSS substrate with ease by FS because at the attained steady state temperature $\left(1020^{\circ} \mathrm{C}\right)$, AISI 316 has adequate flow stress to offer resistance to plastic flow and intermingle with the substrate to form a coating.

IV. Coatings of all the friction-surfaced samples in as-deposited condition show a high level of hardness. The overlapping region of the obtained coating in all the three samples has a higher hardness value than the single coating region.

V. The SEM images of sample 1 show a spherodite micro structure containing small particles of cementite and a continuous phase of austenite.

VI. The multi-layered overlapping ( $3 \mathrm{~mm}$ and $1 \mathrm{~mm}$ on both sides and $3 \mathrm{~mm}$ step-wise) gives a possibility of wide area coverage in FS. In this study, a three-track coating with good bonding was successfully produced. However, crack formation at the interface of the coating and the substrate of single layer in Fig. 8(d) shows the nonexistence of bonding at the edges of the coating.

VII. The EDX analysis indicates the presence of nickel, chromium and oxygen, indicating the formation of oxide compounds.

VIII. It is thus feasible to utilize an AISI 316 tool in the friction surfacing process to produce single and overlapping coatings on HSS to improve corrosion resistance and supply wear protection.

Acknowledgments: The authors would like to thank the workshop personnel at the AALTO University and the authorities of Erasmus Mundus programme for the support of this research.

\section{REFERENCES}

[1] Nicholas ED, (1993) Friction surfacing. In: Olson, D., Siewert, T., Liu, S., Edwards, G.(Eds.), ASM Handbook - Welding, Brazing and Soldering, vol. 6. ASM International, California, pp. 321-323

[2] Sekharbabu R, Rafi HK, Rao KP (2013) Characterization of D2 tool steel friction surfaced coatings over low carbon steel. Materials and Design 50:543-550, DOI:10.1016/j.matdes.2013.03.042

[3] Gandra J, Miranda RM, Vilaca P (2012) Performance analysis of friction surfacing. Journal of Materials Processing Technology 212: 1676-1686, DOI:10.1016/j.jmatprotec.2012.03.013

[4] Klopstock H and Neelands AR: U.K. Patent 572789, 1994.

[5] Dilip JJS, Babu S, Rajan SV, Rafi KH, Janaki Ram GD and Stucker BE (2013) Use of Friction Surfacing for Additive Manufacturing. Materials and Manufacturing Processes, 28:189-194, DOI:10.1080/10426914.2012.677912

[6] Kumar BV, Reddy GM, Mohandas T (2015) Influence of process parameters on physical dimensions of AA 6063 aluminium alloy coating on mild steel in friction surfacing. Defence Technology, XX: 1-7

[7] Dilip JJS, Janaki Ram GD (2013) Microstructure evolution in aluminium alloy AA 2014 during multilayer friction deposition. Material Characterization 86: 146-151, DOI:10.1016/j.matchar.2013.10.009 
R. Kumar, S. Chattopadhyaya, A. Ghosh, G.M. Krolczyk, P. Vilaca, R. Kumar,

M. Srivastava, M. Shariq, R. Triphathi
Characterization of Friction Surfaced Coatings of AISI 316 Tool over High-Speed-Steel Substrate

[8] Stegmueller MJR, Schindele P, Grant RJ (2015) Inductive heating effects on friction surfacing of stainless steel onto an aluminium substrate. Journal of Materials Processing Technology 216: 430-439, DOI:10.1016/j.jmatprotec.2014.10.013

[9] Jujare T, Kumar A, Kailas SV, Bhat K.U (2014) Friction surfacing of mild steel by copper: a feasibility study. Procedia Materials Science 5: 1300 - 1307, DOI:10.1016/j.mspro.2014.07.445

[10] Hanke S, Beyer M, dos Santos JF, Fischer A. (2013) Friction surfacing of a cold work tool steelMicrostructure and sliding wear behaviour. Wear 308: 180-185, DOI:10.1016/j.wear.2013.06.017

[11] Maruda R W, Krolczyk G M, Feldshtein E, Pusavec F, Szydlowski M, Legutko Stanislaw, SobczakKupiec A. (2016) A study on droplets sizes, their distribution and heat exchange for minimum quantity cooling lubrication (MQCL). International Journal of Machine Tools \& Manufacture100 81-92, DOI:10.1016/j.ijmachtools.2015.10.008

[12] Kumar R, Chattopadhyaya S, Hloch S, Krolczyk G, Legutko S. (2016) Wear Characteristics and Defects analysis of Friction Stir Welded joint of Aluminium alloy 6061-T6. Eksploatacja i NiezawodnoscMaintenance and Reliability 18: 128 - 135, DOI:10.17531/ein.2016.1.17

[13] Ruggiero A, Valasek P, Müller M, "Exploitation of Waste Date Seeds of Phoenix Dactylifera in Form of Polymeric Particle Biocomposite: Investigation on Adhesion, Cohesion and Wear", Composites Part B 104 (2016) 9-16, DOI:10.1016/j.compositesb.2016.08.014

[14] Vilaca P, Hanninen H, Saukkonen T, Miranda RM (2014) Differences between secondary and primary flash formation on coatings of HSS with AISI 316 using Friction Surfacing. Weld World 58:661-671, DOI: $10.1007 / \mathrm{s} 40194-014-0148-5$

[15] Gandra J, Pereira D, Miranda RM, Silva RJC, Vilaca P (2013) Deposition of AA6082-T6 over AA2024T3 by friction surfacing- Mechanical and wear characterization. Surface \& Coatings Technology 223:3240, DOI:10.1016/j.surfcoat.2013.02.023

[16] Puli R, Janaki Ram GD (2012) Microstructures and properties of friction surfaced coatings in AISI 440C martensitic stainless steel. Surface and coatings Technology 207:310-318, DOI:10.1016/j.surfcoat.2012.07.001

[17] Kaplonek W, Nadolny K and Habrat W, "Morphology of Near- and Semispherical Melted Chips after the Grinding Processes Using Sol-Gel Abrasives Based on SEM-Imaging and Analysis", Hindawi Publishing Corporation Advances in Materials Science and Engineering Volume 2016, Article ID 2573920, 12 pages, DOI:10.1155/2016/2573920

[18] Jozwik J, Mika D, " Diagnostics of Workpiece Surface Condition Based on Cutting Tool Vibrations During Machining", Advances in Science and Technology Research Journal Volume 9, No. 26, June 2015, pages 57-65, DOI:10.12913/22998624/2365

[19] Puli R, Janaki Ram GD (2011) Characterization of friction surfaced martensitic stainless steel (AISI 410) coatings. Transactions of the Indian Institute of Metals 64:41-45, DOI:10.1007/s12666-011-0008-6

[20] Puli R, Janaki Ram GD (2012) Corrosion performance of AISI 316L friction surfaced coatings. Corrosion Science 62:95-103, DOI:10.1016/j.corsci.2012.04.050

[21] Maruda R W, Legutko S, Krolczyk G M, Raos P, " Influence of Cooling Conditions on the Machining Process Under MQCL And MQL Conditions" Technical Gazette 22, 4(2015), 965-970, DOI:10.17559/TV-20140919143415

[22] Govardhan D, Kumar ACS, Murti KGK, Reddy GM (2012) Characterization of austenitic stainless steel friction surfaced deposit over low carbon steel. Materials \& Design 36:206-214, DOI:10.1016/j.matdes.2011.07.040

[23] Rao KP, Sankar A, Rafi HK, Janki Ram GD, Reddy GM (2013), Friction surfacing on nonferrous substrates: a feasibility study. Int. J Adv Manuf Technology 65:755-762, DOI: $10.1007 / \mathrm{s} 00170-012-4214-0$

[24] Zavareh M.A, Sarhan A.A.D.M, Razak B.B, Basirun W.J, "The tribological and electrochemical behaviour of HVOF-sprayed $\mathrm{Cr} 3 \mathrm{C} 2-\mathrm{NiCr}$ ceramic coating on carbon steel", Ceramics International 41(2015)5387-5396, DOI:10.1016/j.ceramint.2014.12.102

[25] Zavareh M.A, Sarhan A.A.D.M, Razak B.B, Basirun W.J, "Plasma thermal spray of ceramic oxide coating on carbon steel with enhanced wear and corrosion resistance for oil and gas applications", Ceramics International 40(2014)14267-14277, DOI:10.1016/j.ceramint.2014.06.017 
Characterization of Friction Surfaced Coatings of

AISI 316 Tool over High-Speed-Steel Substrate
R. Kumar, S. Chattopadhyaya, A. Ghosh, G.M. Krolczyk, P. Vilaca, R. Kumar, M. Srivastava, M. Shariq, R. Triphathi

[26] Zavareh M.A, Sarhan A.A.D.M, Razak B.B, Basirun W.J, "Electrochemical Characterizations of Different Ceramic Composite Coatings on Carbon Steel Piping Using High Velocity Oxy-fuel Spray", Proceedings of the World Congress on Engineering and Computer Science 2014 Vol II WCECS 2014, 22-24 October, 2014, San Francisco, USA

[27] Ruggiero A, Merola M, Carlone P, Archodoulaki VM, "Tribo-mechanical characterization of reinforced epoxy resin under dry and lubricated contact conditions", Composites Part B 79 (2015) 595-603, DOI:10.1016/j.compositesb.2015.05.015

[28] Ruggiero A, Amato RD, Gómez E, " Experimental Analysis of tribological behaviour of UHMWPE against AISI420C and against TiAl6V4 alloy under dry and lubricated conditions" Tribology International 92 (2015) 154-161, DOI:10.1016/j.triboint.2015.06.005

[29] Merola M, Ruggiero A, Mattia JSD, Affatato S, "On the tribological behavior of retrived hip femoral heads affected by metallic debris. A comparative investigation by stylus and optical profilometer for a new roughness measurement protocol", Measurement 2016, DOI:10.1016/j.measurement.2016.05.003

[30] Sekharbabu R, Rafi HK, Rao KP (2013) Characterization of D2 tool steel friction surfaced coatings over low carbon steel. Materials and Design 50:543-550, DOI:10.1016/j.matdes.2013.03.042

[31] Bauser, M., Sauer, G., Siegert, K. (Eds.), 2006. ASM Handbook, vol. 2, 2nd ed. ASM International, Materials Park, OH 44073-0002, p. 917 (vol. 14, p. 566).

[32] Khalid Rafi, H., Balasubramaniam, K., Phanikumar, G., Prasad Rao, K., (2011). Thermal profiling using infrared thermography in friction surfacing. Met. Mater. Trans. 42A, 3425-3429, DOI:10.1007/s11661-011-0750-8

[33] Rao KP, Sreenu AV, Rafi HK, Libin MN, Balasubramaniam K (2012). Tool steel and copper coatings by friction surfacing - A thermography study, Journal of Materials Processing Technology 212:402- 407, DOI:10.1016/j.jmatprotec.2011.09.023

[34] Gandra J, Miranda RM, Vilaca P, Krohn H, Beyer M., Dos Santos JF, (2014) Friction surfacing - a review. J. Mater. Process. Technol. 214:1062-1093, DOI:10.1016/j.jmatprotec.2013.12.008

[35] Puli R, Janaki Ram GD (2012) Wear and corrosion performance of AISI 410 martensitic stainless steel coatings produced using friction surfacing and manual metal arc welding, Surface \& Coatings Technology 209: 1-7, DOI:10.1016/j.surfcoat.2012.06.075 
R. Kumar, S. Chattopadhyaya, A. Ghosh, G.M. Krolczyk, P. Vilaca, R. Kumar, M. Srivastava, M. Shariq, R. Triphathi
Characterization of Friction Surfaced Coatings of AISI 316 Tool over High-Speed-Steel Substrate
Submitted: $\quad$ 15.01.2016

Accepted: $\quad$ 14.11.2016

\section{Ravi Kumar}

Mechanical Engineering Department. IIT (ISM), Dhanbad Jharkhand. India Mechanical Engineering Department.

B.T.Kumaon Institute of Technology Dwarahat Almora, Uttarakhand. India

Somnath Chattopadhyaya

Mechanical Engineering Department. IIT (ISM), Dhanbad Jharkhand. India

\section{Aniruddha Ghosh}

Mechanical Engineering Department. GCETT Berhrampore, West Bengal. India

Grzegorz M. Krolczyk

Faculty of Mechanical Engineering Opole University of Technology. Poland

\section{Pedro Vilaca}

Facuty of Department of Engineering Design \& Production, Aalto University. Finland

\section{Ratnesh Kumar}

Mechanical Engineering Department. IIT (ISM), Dhanbad Jharkhand. India Mechanical Engineering Department NIT Jamshedpur Jharkhand. India

\section{Madhulika Shrivastava}

Mechanical Engineering Department. IIT (ISM), Dhanbad Jharkhand. India

Mohammad Shariq

Mechanical Engineering Department. IIT (ISM), Dhanbad Jharkhand. India

Rupam Tripathi

Mechanical Engineering Department. IIT (ISM), Dhanbad Jharkhand. India 